\title{
Application of Static Var Generator in Low-voltage Drilling Power Grid of Drilling Industry Applications
}

\author{
Chen Shuchun ${ }^{1, \mathbf{a}}$, Li Jiaxuan ${ }^{2, \mathbf{b}}$, Wang Wenzhong ${ }^{3, \mathbf{c}}$, Liu Yang ${ }^{1, \mathbf{d}}$ \\ ${ }^{1}$ Hebei Software Institute, Baoding, 071001, China \\ ${ }^{2}$ North China Electric Power University, Beijing, 102206, China \\ ${ }^{3}$ Baoding SifangSanyi Electric Company, Baoding, 071000, China \\ aemail: 13833005036@163.com, bemail: elisejxli@163.com, 'email: \\ 13903223430@163.com, demail: 45384512@qq.com
}

Keywords: Static Var Generator (SVG), reactive power compensation, drilling rig

\begin{abstract}
Drilling industry operates under low-voltage power network, causes large number of reactive power loss, and seriously affects the power system voltage stability. This paper introduces the application of Static Var Generator (SVG) reactive power compensation in the low-voltage drilling power network using the fuzzy control of PI parameters online adjustment, and detailed demonstrates the way to select and design the programs. The basic principle, workflow and field system test of SVG reactive power compensation are also presented. The experimental results show that the application of SVG can improve power quality, raise the power factor, and reduce the voltage fluctuation, also provide references for SVG research experience in other areas.
\end{abstract}

\section{Introduction}

Oil drilling industry leads to a large number of reactive power consumption, resulting in poor stability of the power system. AC-DC conversion during the operation of DC electric drive drilling rig will produce a large amount of harmonic wave components, which causes serious pollution to the power supply system [1]. Meanwhile, the harmonic pollution makes drilling system usually run with power factor under 0.5, and generators cannot be fully utilized, which increases the investment of equipment and energy consumption. The method of quickly and effectively compensating reactive load of mine power network is in urgent need. Over the last couple of decades, researchers and engineers have made path-breaking research on this technology [2-4]. For this type of electricity load, static type dynamic compensator is more suitable. SVG is one of important static reactive power compensation devices [5]. With appropriate control strategy [6], SVG may have functions of reactive power compensation and harmonic suppression. This paper uses the bridge structure to build SVG main circuit, and the fuzzy control of PI parameters online adjustment as a control strategy, which has the advantages of easy operation and can adjust reactive power and voltage rapidly. Then verifies the feasibility of the control method by MATLAB simulation and field system test.

\section{Working principle and workflow of SVG}

Working principle of SVG. SVG (Static Voltage Generator) is one of the most important devices of flexible AC transmission systems, which can be divided into the voltage-source SVG (DC side using capacitive) and the current-source SVG (DC side using inductor). The former is more use in practice, due to the characteristics of its simple structure, small energy loss, low cost and easy control. Take voltage-source SVG as an example to describe the working principle (Fig. 1).

In order to make self-commutated bridge circuit absorb or emit reactive current and achieve dynamic reactive power compensation, parallel the circuit to power line through reactance, then control the AC side current, or adjustment its AC output phase and amplitude of positive appropriately. 


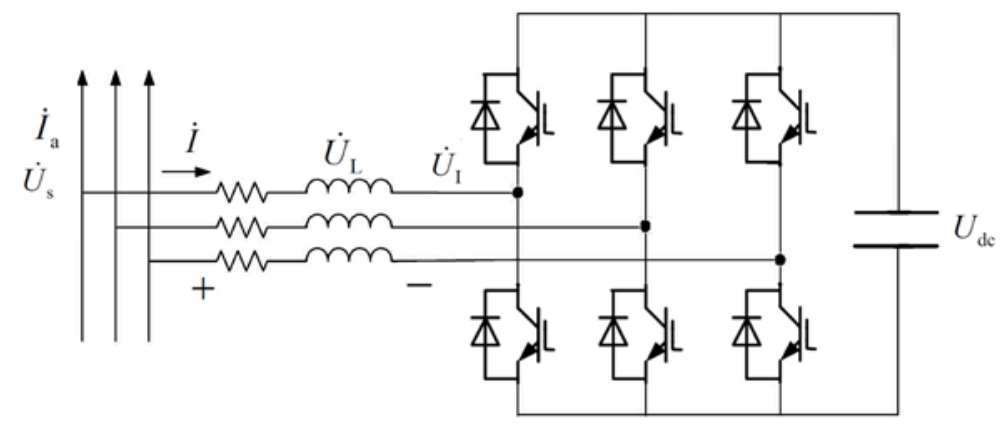

Fig. 1 The main circuit of the SVG

The results of experiment show that if the output voltage of SVG is higher than the system voltage, current will be generated ahead of $90^{\circ}$, SVG working in a capacitive state. If the output voltage is bellower, a $90^{\circ}$ lagging current will be generated, and SVG is operating in inductive state.

\section{Select and design the program of SVG applications in low-voltage drilling project}

Program selection. Oil drilling electric drive SCR system has the following characteristics: voltage flicker, reactive power ranges large. With the different number of turned on drilling, hardness drilling rocks, different reactive power demand drastic changes at different depths. During the rig going down, reactive power changes quickly, thus, SCR is a typical kind of impact-resistance reactive power load and need a sufficient amount of reactive power compensation timely. For this type of electricity load, static type dynamic compensator is more suitable.

Oil drilling electric drive SCR system operates under small low-voltage network, full-load Reactive power demand is about $1000 \mathrm{kvar}$, with the load of four oil drilling rigs, illumination, and other accessory device. According to the site statistics of three months, reactive power demand less than $700 \mathrm{kvar}$, and four generators are not usually at the same time generate electricity. From the above reasons, take 700kvar as the SVG reactive demand limit, for resource saving. Generator excitation regulator starts manually to regulate reactive when the reactive power demand exceeds $700 \mathrm{kvar}$ system alarms. Effectively increased the efficiency of the generator, reduced the capacity, volume and weight of SVG, and decreased the area by nearly a third.

\section{Program design.}

1. Circuit pulse controlled optical transmission interface. One side connected to the main bridge circuit of SVG, the other side accessed to SVG's real-time controller. The controller interface consists of fiber-optic and control equipment, main achievement is interworking SVG main circuit valve and controller. That is, transmitted the pulse command from the controller to the SVG main circuit valve, and delivery the SVG main circuit valve information to the controller timely.

2. Master system. Master System is a complex signal processing system consists of a large number of digital circuits, analog circuits, and DSP processors and other components.

(1) Measured the three-phase currents and three-phase voltage signals of the system, converted to analog signals that A / D converter can accept.

(2) Converse the analog signal to digital, input DSP controller, get reactive and RMS voltage signal, then input it to the pulse trigger according to control principle

(3) Pulse trigger generates a pulse to trigger inverter IGBT of the main circuit, which in turn drives IGBT generate the reactive power grid system required.

3. Signal monitoring and processing circuit. Signal monitoring and processing circuit mainly used for variables measurement and processing, provide the necessary inputs to the display operator, real-time control and protection circuitry.

4. Status monitor and control management. This is a common compensation equipment monitoring module that monitors the core and the auxiliary member, connected to the real-time controller, main circuit of SVG, cooling systems, power supplies, circuit breakers, switches, and communication between the SCADA systems. 
5. Human machine interface. Usually run on industrial PC, with images and back-office support software. Users could control the compensator through routine operation, detection and diagnosis situations of the whole and each constituent part.

\section{Key technology and application effect of SVG in low-voltage drilling project.}

To stabilize the quality of power grid, apply SVG static dynamic reactive power compensation devices to dynamic reactive power compensation device, specific programs are as follows:

Installed a group of SVG (capacity of $\pm 12 \mathrm{Mvar}$ ) and supporting FC devices in low-voltage side bus of large impact load main transformer.

Test three kinds of operation modes of 4 sets of SVG:

1. Constant power mode: power value is constant, and does not change according to the grid.

2. Constant power factor mode: target value of input power factor is constant. SVG tracking system power factor automatically, adjusting the size and properties of output reactive power, so that the power factor could be accurately controlled within a given range.

3. Constant voltage mode: entering the target value of system voltage, SVG tracking system voltage fluctuations automatically, adjusting the size and properties of output reactive power, so that the system voltage could be accurately controlled within a given range.

From the experimental results, take $35 \mathrm{kV}$, III, voltage stabilized mode as an example, which target voltage value of SVG is $35.5 \mathrm{kV}$. During the time of testing, the system maximum phase voltage is $20.699 \mathrm{kV}$, minimum system phase voltage $19.492 \mathrm{kV}$. Voltage extremes are $20.01 \mathrm{kV}$ and $19.541 \mathrm{kV}$ (Fig. 2). A maximum unbalance of three-phase voltage is $1.06 \%$ (Fig. 3). Harmonic content of the voltage waveform floats between $0.17 \%-1.06 \%$ (Fig. 4). The average of phase voltage ranges from $19.610 \mathrm{kV}$ to $20.685 \mathrm{kV}$ (Fig. 5). That is, the system line voltage in the range of $35.83 \mathrm{kV}-34.00 \mathrm{kV}$.

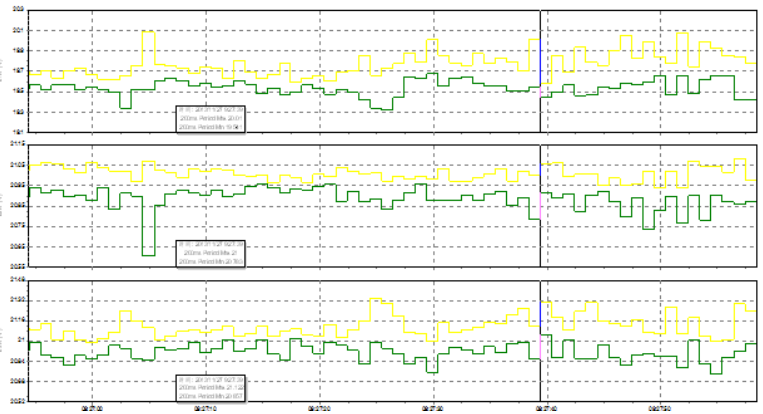

Fig. 2 Voltage fluctuations

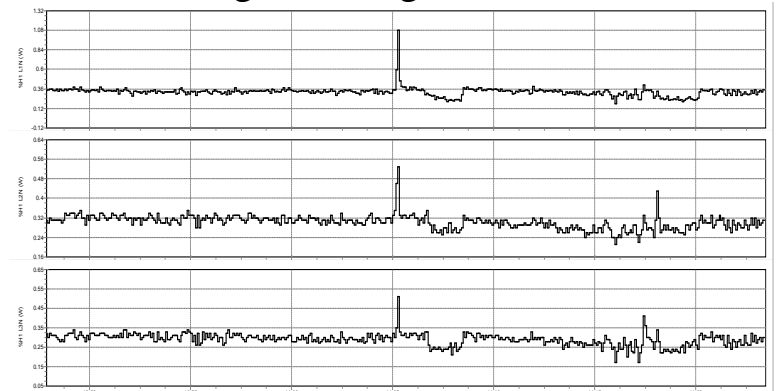

Fig.4 harmonic voltage

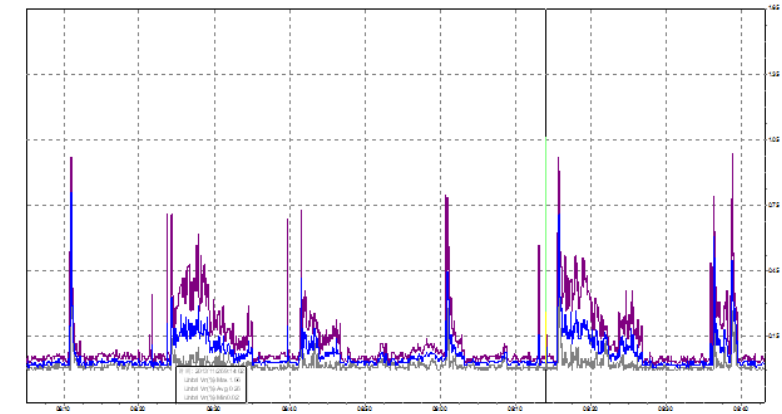

Fig. 3 Unbalance

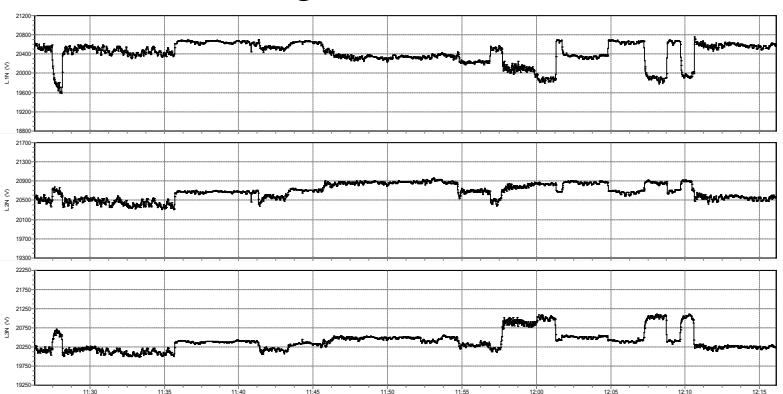

Fig.5 Voltage surges and sags

When system current and reactive power demands change, SVG can adjust the output size of reactive power compensation quickly. Moreover, power factor can be well controlled in the specified range. SVG tracking changes in system current and make adjustments extremely fast, for level of millisecond.

In summary, in the voltage stabilized mode, voltage deviation, voltage fluctuations, voltage surges and sags, unbalance and harmonic voltage are all meet the national requirements. Similarly, experimental results of $35 \mathrm{kV}$ IV, $10 \mathrm{kV}$ III, $10 \mathrm{kV}$ IV meet national standards and design expectations.

Consolidation of project experimental data as follows: 
Table 1 SVG operation mode data

\begin{tabular}{|c|c|c|c|c|c|}
\hline $\begin{array}{c}\text { Measuring } \\
\text { point }\end{array}$ & $\begin{array}{c}\text { Voltage } \\
\text { deviation }\end{array}$ & $\begin{array}{c}\text { Voltage } \\
\text { fluctuations }\end{array}$ & $\begin{array}{c}\text { Unbalance } \\
\text { (negative } \\
\text { sequence) }\end{array}$ & $\begin{array}{c}\text { Harmonic } \\
\text { voltage } \\
\text { (device) }\end{array}$ & $\begin{array}{c}\text { Voltage surges and } \\
\text { sags }\end{array}$ \\
\hline $35 \mathrm{kV}$ III & $5.8 \%$ & $2.3 \%$ & $1.06 \%$ & $0.17 \%-1.06 \%$ & $35.83[\mathrm{kV}]-34.00[\mathrm{kV}]$ \\
\hline $35 \mathrm{kV}$ IV & $2.3 \%$ & $1.6 \%$ & $1.18 \%$ & $0.6 \%-1.57 \%$ & $35.947[\mathrm{kV}]-34.27[\mathrm{kV}]$ \\
\hline $10 \mathrm{kV}$ III & $4.9 \%$ & $2.6 \%$ & $0.97 \%$ & $1.5 \%-2.94 \%$ & $10.5[\mathrm{kV}]-10[\mathrm{kV}]$ \\
\hline $10 \mathrm{kV} \mathrm{IV}$ & $1.1 \%$ & $1.9 \%$ & $0.97 \%$ & $0.64 \%-1.57 \%$ & $10.02[\mathrm{kV}]-10.53[\mathrm{kV}]$ \\
\hline
\end{tabular}

\section{Summary}

1. SVG dynamic reactive power compensation device can adjust the reactive power output in rapid succession dynamically, improve the power factor, maximize meet requirements for power factor compensation, power factor close to 1.0 any time. So that the efficiency is greatly improved, investment in equipment is high-yield.

2. SVG also has the following characteristics: the ability to regulate strongly, the low harmonic content, the small size of devices, no noise and low loss.

3. In order to give quick response to the compensation process, the fuzzy control of PI parameters online adjustment can improve the dynamic performance of the device.

\section{References}

[1] Dang C.L., Yan J.C., Song W.C. and Zhang X.Y.: Power Electronics Vol.10 (2010), p. 035.

[2] Singh B., Saha R., Chandra A. and Al-Haddad K.:Power Electronics, IET Vol. 2 (2009), p. 297-324.

[3] El-Moursi M. S. and Sharaf, A. M.: Power Systems, IEEE Transactions on Vol. 20 (2005), p. 1985-1997.

[4] Majumder R.: Industrial Electronics, IEEE Transactions on Vol. 60(4) (2013), p. 1403-1416.

[5] Lu Q., Ni W., Wang X. and Zhuang L.: Control and Decision Conference (CCDC), 2011 Chinese(2011), p. 3653-3657

[6] Li K., LIU J., Wei B. and WANG Z.A.: Proceedings of the CSEE Vol. 26 (2006), p. 58-63. 